http://jmscr.igmpublication.org/home/

ISSN (e)-2347-176x ISSN (p) 2455-0450

crossref DOI: https://dx.doi.org/10.18535/jmscr/v7i10.119

Journal Of Medical Science And Clinical Research

\title{
A Case of Klinefelter Syndrome (47, XXY) with Patent Ductus Arteriosus - A Rare Case Report
}

\author{
Prof.Dr M.Senthilvelan ${ }^{1}$, Dr S.Gopikumar ${ }^{2}$, Dr K.Baburaj ${ }^{3}$, Dr A.Elaiyaraja ${ }^{4}$ \\ ${ }^{1}$ Professor\& HOD, Department of Medicine, Rajah Muthiah Medical College \\ ${ }^{2}$ Post Graduate, Department of Medicine, Rajah Muthiah Medical College \\ ${ }^{3}$ Professor, Department of Medicine, Rajah Muthiah Medical College \\ ${ }^{4}$ Senior Resident, Department of Medicine, Rajah Muthiah Medical College
}

\begin{abstract}
Patent Ductus Arteriosus (PDA) is extraordinarily not often reported in Klinefelter Syndrome 47, XXY. Herein, we mentioned one case of 47, XXY karyotype with PDA and reviewed the to be had literature. The phenotypic traits of the 18 Years Old Male showed the presence of capabilities regular of Klinefelter Syndrome (47, XXY) like tallest in his circle of relatives, Gynecomastia and absent secondary sexual characteristics. Karyotype analysis indicates 47, XXY. 2D echocardiogram detection showed congenital heart disease - patent ductus arteriosus (PDA 0.3cm size).

Keywords: Klinefelter Syndrome 47, XXY, Patent Ductus Arteriosus (PDA).
\end{abstract}

\section{Introduction}

Klinefelter syndrome $^{[1]}$ (KS), also known as 47, $\mathrm{XXY}$ or $\mathrm{XXY}$, is the set of signs that result from or greater $X$ chromosomes in males. ${ }^{[7]}$ The number one features are infertility and small testicles. ${ }^{[7]}$ Often, symptoms may be subtle and lots of human beings do now not understand they're affected. ${ }^{[6]}$ Sometimes, signs and symptoms are greater prominent and may consist of weaker muscular tissues, greater top, negative coordination, less body hair, breast enlargement, and much less interest in intercourse. ${ }^{[6]}$ Often it's miles handiest at puberty that these signs and symptoms are observed. ${ }^{[3]}$ Intelligence is generally normal; however, analyzing problems and problems with speech are extra not unusual. ${ }^{[6]}$ Symptoms are normally greater severe if three or greater $\mathrm{X}$ chromosomes are gift (48, XXXY syndrome or $49, \mathrm{XXXXY}$ syndrome). ${ }^{[6]}$ Klinefelter syndrome is one of the maximum common chromosomal problems, occurring in one to two in line with 1,000 live male births. ${ }^{[2,5]}$ It is known as after the endocrinologist Harry Klinefelter, who recognized the circumstance inside the Nineteen Forties. In 1956 , identification of the more $X$ chromosome turned into first observed. Mice can also have the XXY syndrome, making them a beneficial studies version. By adulthood, XXY men appearance much like men without the circumstance, even though they're often taller. In adults, possible traits range widely and encompass little to no signal of affectedness, a lanky, youthful construct and facial appearance, or a rounded frame kind with some diploma of gynecomastia (expanded breast tissue). Gynecomastia is present to a degree in about a third of affected individuals, a barely better percentage than in the XY population. The time period hypogonadism in XXY signs is regularly 
misinterpreted to intend "small testicles" whilst it means reduced testicular hormone/endocrine feature. Because of this hypogonadism, people often have a low serum testosterone level, but high serum follicle-stimulating hormone and luteinizing hormone levels. Despite this false impression of the time period, however, XXY guys may have microorchidism (i.e., small testicles).

The testicle length of affected adult males are usually less than $2 \mathrm{~cm}$ in period (and continually shorter than $3.5 \mathrm{~cm}), 1 \mathrm{~cm}$ in width, and $4 \mathrm{ml}$ in quantity. Several epidemiological research have verified an expanded mortality from cardiovascular reasons in patients with Klinefelter Syndrome (KS). Little facts is available approximately the character of the underlying cardiovascular abnormalities.

\section{Case Report}

An 18 Years Old male offered to our department with features suggestive of Klinefelter Syndrome (KS) like absent secondary sexual characteristics, gynecomastia, tall stature, small testicle of extent $<0.5 \mathrm{ml}$, free T4 $1.19(0.89-1.76 \mathrm{ng} / \mathrm{dL}), \mathrm{TSH}$ $2.15(0.35-5.50 \mu \mathrm{IU} / \mathrm{mL}, \quad \uparrow \mathrm{FSH}-36.01(1.5-$ $12.4 \mathrm{mIU} / \mathrm{ml}), \uparrow$ LH $28.75(1.24-7.8 \mathrm{mIU} / \mathrm{ml})$, PROLACTIN $-9.06(2.1 \quad-17.7 \quad \mathrm{ng} / \mathrm{ml})$ $\downarrow$ TESTOSTERONE - 154.68 (241 - $827 \mathrm{ng} / \mathrm{dL})$. Further we evaluated the patient and we did Karyotype evaluation which shows 47, XXY one extra $\mathrm{X}$ chromosomes. 2D echocardiogram detection showed congenital heart disorder patent ductus arteriosus (PDA $0.3 \mathrm{~cm}$ size). X-ray obliteration of aortopulmonary window.

Figure 1: Karyotype analysis indicates 47, XXY

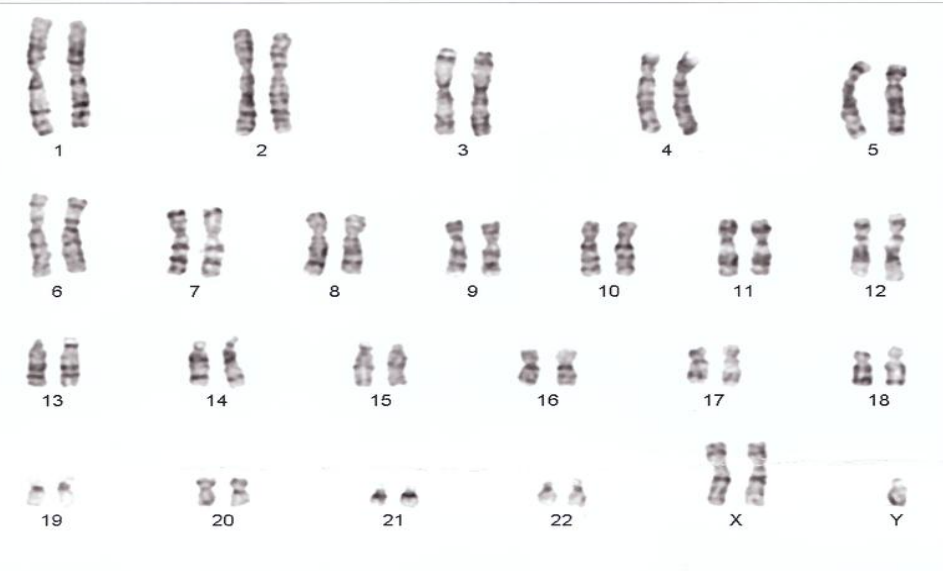

Figure2: Echocardiogram showing patent ductus arteriosus.

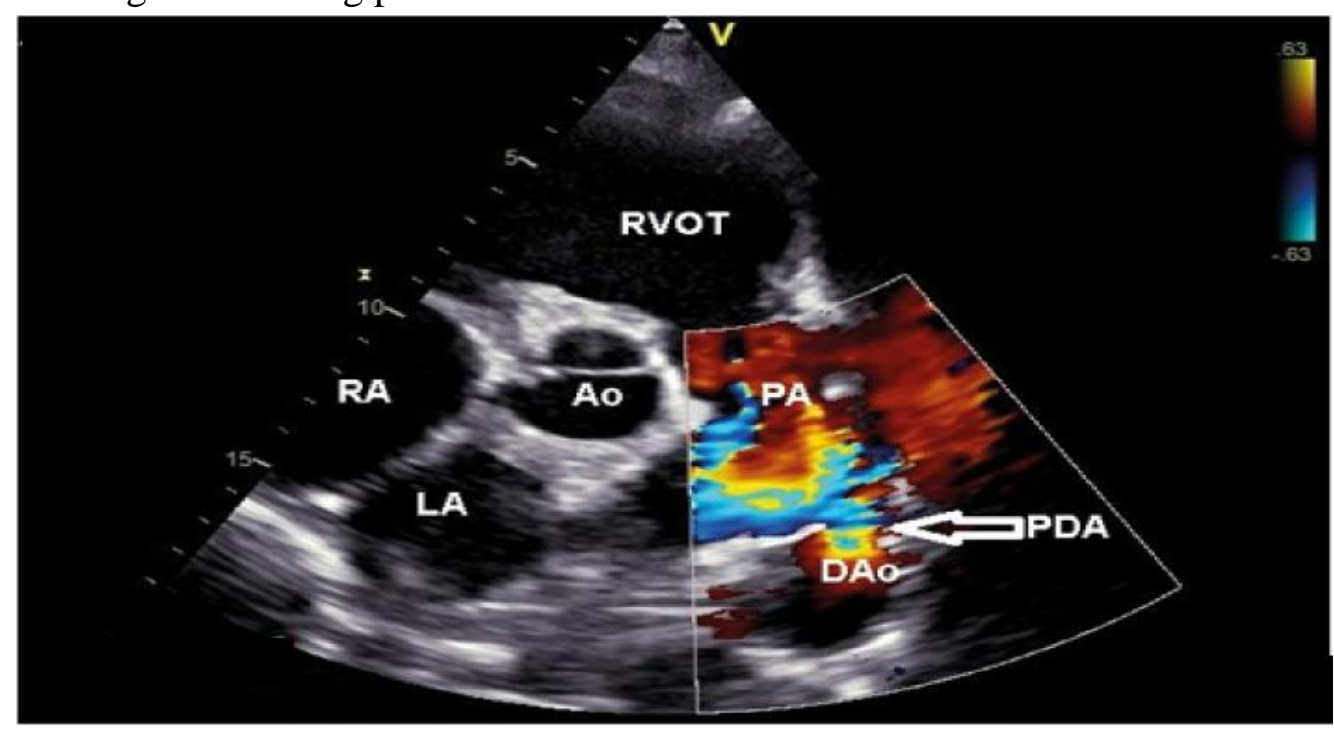




\section{Discussion}

Klinefelter syndrome (KS), additionally known as $47, \mathrm{XXY}$ or XXY, is the set of signs and symptoms that result from two or greater $X$ chromosomes in adult males. ${ }^{[7]}$ The primary features are infertility and small testicles ${ }^{[7]}$ Often, symptoms can be diffused and many people do not realize they're affected. ${ }^{[6]}$ Sometimes, signs and symptoms are more outstanding and might include weaker muscular tissues, extra peak, negative coordination, less body hair, breast increase, and less interest in intercourse. ${ }^{[6]}$ Often it is best at puberty that these symptoms are noticed. ${ }^{[3]}$ Intelligence is generally normal everyday; but, analyzing difficulties and problems with speech are greater common place. ${ }^{[6]}$ Symptoms are typically greater extreme if three or more $\mathrm{X}$ chromosomes are present (48, XXXY syndrome or $49, \mathrm{XXXXY}$ syndrome). This 18 years antique male a case of Klinefelter syndrome, presented for absent secondary sexual characteristics and echocardiogram shows patent ductus arteriosus-an extraordinary presentation. ${ }^{[4]}$

\section{Conclusion}

An uncommon presentation of patent ductus arteriosus within the case of Klinefelter syndrome. An 18 year old male presented with features suggestive of Klinefelter syndrome and we evaluated the affected person and the Karyotype analysis indicates 47, XXY and echocardiogram shows features suggestive of patent ductus arteriosus.

\section{References}

1. Klinefelter syndrome". rarediseases. info.nih.gov. Retrieved 15 April 2019.

2. "How many people are affected by or at risk for Klinefelter syndrome (KS)?". Eunice Kennedy Shriver National Institute of Child Health and Human Development. 2012-1130. Archived from the original on 17 March 2015. Retrieved 15 March 2015.
3. "How do health care providers diagnose Klinefelter syndrome (KS)?". Eunice Kennedy Shriver National Institute of Child Health and Human Development. 2012-1130. Archived from the original on 17 March 2015. Retrieved 15 March 2015.

4. "Is there a cure for Klinefelter syndrome (KS)?". Eunice Kennedy Shriver National Institute of Child Health and Human Development. 2012-11-30. Archived from the original on 17 March 2015. Retrieved 16 March 2015.

5. "Klinefelter syndrome". Genetics Home Reference. National Library of Medicine. 2012-10-30. Archived from the original on 2012-11-15. Retrieved 2012-11-02.

6. "What are common symptoms of Klinefelter syndrome (KS)?". Eunice Kennedy Shriver National Institute of Child Health and Human Development. 2013-10-25. Archived from the original on 2 April 2015. Retrieved 15 March 2015.

7. "Klinefelter Syndrome (KS): Overview". nichd.nih.gov. Eunice Kennedy Shriver National Institute of Child Health and Human Development. 2013-11-15. Archived from the original on 18 March 2015. Retrieved 15 March 2015. 